\title{
Síndrome de Sezary como causa de prurito en el anciano
}

\author{
J. M. Pinar Manzanet, C. Belló González, C. González Muñoz \\ Médicos de Familia. C.S. Águilas. Madrid
}

Sezary syndrome as pruritus cause in old age

\section{RESUMEN}

El prurito puede definirse como una sensación especial de la piel, fisiológica o patológica, que incita a rascarse. Puede ser provocado por múlti ples causas, por lo que el prurito por piel seca, es pecialmente en ancianos, es un diagnóstico que no debemos realizar demasiado rápidamente sin an tes excluir otras causas de prurito, tanto cutáneas (psoriasis, neoplasias,...) como internas (fárma cos, ferropenia, hiper o hipotiroidismo, etc.).

Presentamos el caso de una mujer de 87 años de edad con prurito de larga evolución, cuyo estu dio se completó con el diagnóstico de síndrome de Sezary, expresión leucémica de la micosis fungoi de (linfoma cutáneo de células T).

Abordamos también el diagnóstico diferencial del prurito crónico, su manejo, así como la nece saria relación entre Atención Primaria y Especia lizada.

Palabras clave: Prurito. Linfoma cutáneo. Sín drome de Sezary.

\begin{abstract}
Pruritus can be defined as a "special sensation" in the skin, physiological or pathological, that moves to scratch. It can appear because of many causes so, diagnosis of pruritus due to "dry skin" mustn't be done too quickly (specially in old age) without excluding previously other pruritus causes, both cutaneous (as psoriasis, neoplasias, etc.) both internal (drugs, iron-deficiency, hyper or hypothy roidism, etc.).

We report the case of a 87 years old woman com plaining a long evolution pruritus, whose study was concluded as Sezary syndrome, leukemic expression of mycosis fungoides (cutaneous T-cell lymphoma).

We also explain differential diagnosis of chronic pruritus, its management and the necessary rela tion between Primary Health Care and Specialized Assistance.
\end{abstract}

Key words: Pruritus. Cutaneous lymphoma. Se zary syndrome.

\section{INTRODUCCIÓN}

La sensación de prurito puede aparecer en cualquier localización de la piel, compartiendo receptores y vías nerviosas con la sensación dolorosa. Dicha sensación constituye, además, un motivo frecuente de consulta en nuestro quehacer diario, por fortuna banal en la mayoría de los casos. No obstante, en algunas ocasiones, se trata del primer síntoma de un proceso subyacente, especialmente en situaciones de prurito generalizado, crónico y sin claras lesiones dermatológicas.

Estas situaciones nos obligan, como médicos de Atención Primaria, a un seguimiento de esos pacientes, así como a un diagnóstico diferencial entre numerosos procesos (que más tarde abordaremos), a fin de realizar un diagnóstico, al menos de sospecha, principal objetivo a nuestro nivel, para des- 
pués proceder a eventuales derivaciones a atención especializada. Dicho diagnóstico precoz resultó importante en el caso que presentamos, síndrome de Sezary, entidad cuyo abordaje en los primeros estadios puede ser importante para la posterior evolución.

\section{OBSERVACIÓN CLÍNICA}

Nuestra paciente es una mujer de 87 años de edad, sin antecedentes familiares de interés y con insuficiencia venosa crónica y artrosis como únicos antecedentes personales a destacar.

Durante los últimos 3 años, la paciente venía refiriendo cuadro de prurito generalizado, con reagudizaciones periódicas, sin lesiones cutáneas ni ninguna otra sintomatología acompañante. La clínica cedía sólo parcialmente con el uso de antihistamínicos. Pese a la aparente banalidad del síntoma, se realizó un seguimiento de la paciente, que fue clave para el diagnóstico final. Se realizaron analíticas y exploraciones periódicas, siempre dentro de los parámetros de la normalidad, salvo discreta eosinofilia en alguna de las analíticas. Parásitos en heces y látex equinococo: negativos.

Sin embargo, en los últimos 3-4 meses, su exploración comenzó a presentar cambios significativos. A frecuentes infecciones respiratorias, se unió una eritrodermia difusa con importante descamación de cuero cabelludo y extremidades junto a xerosis cutánea con consistencia de infiltrado. Asímismo, le fueron detectadas pequeñas adenopatías laterocervicales y axilares $(<0,5$ centímetros de diámetro), rodaderas, no dolorosas. El resto de anamnesis por aparatos fue negativa, salvo importante astenia referida por la paciente.

El control analítico realizado entonces mostró datos de anemia normocítica (Hemoglobina: 9,8 g/dl; Volumen Corpuscular Medio: 78 fl) y leucocitosis leve $\left(12,6 \times 10^{3}\right.$ leucocitos $\left./ \mathrm{mm}^{3}\right)$, con linfocitos atípicos en la muestra.

Tanto la clínica como los datos analíticos orientaron el diagnóstico hacia la sospecha de proceso linfoproliferativo-infiltrativo, por lo que se contactó con el servicio de Dermatología para la toma de biopsia cutánea, que resultó compatible con micosis fungoide (linfoma cutáneo de células T).

Dada la avanzada edad de la paciente, pero muy aceptable calidad de vida, en este punto del estudio se consensuó con su familia el continuar con la investigación para averiguar si, como se sospechaba, existía afectación hematológica. Así, se realizó medulograma, que mostró marcadores compatibles con síndrome de Sezary, expresión leucémica del linfoma T cutáneo. El cuadro cutáneo presentó mejoría sintomática con el uso de emolientes y corticoides tópicos. Ultimamente, se inició tratamiento tópico con mostaza nitrogenada, con buena tolerancia de la paciente.

\section{DISCUSIÓN}

El prurito es un frecuente motivo de consulta aunque, por fortuna, banal en la gran mayoría de los casos. No obstante, en casos de larga evolución y, especialmente, en edades avanzadas debe ser objeto de seguimiento y diagnóstico diferencial entre numerosas entidades ${ }^{1}$, reflejadas en la tabla I. ${ }^{2}$

Como en todo el resto de procesos, los recursos habitualmente a nuestro alcance en las consultas son las que emplearemos para realizar ese enfoque diagnóstico del prurito:

1. Anamnesis.- Interrogaremos sobre su intensidad, localización (si es generalizado o localizado, ya que el prurito anovulvar puede ser típico de diabéticos o el nasal de tumores del sistema nervioso central), momento del día en que aparece ( si le despierta por la noche orientará sobre su naturaleza orgánica, sarna o naturaleza psicógena. De noche aumenta la actividad parasimpática y la vasodilatación aumenta el prurito). Investigaremos también sobre alergias conocidas, convivencia con animales, viajes, profesión del paciente, síntomas asociados y toma de fármacos y drogas.

2. Exploración física.- Realizaremos una exploración completa de la piel, con el paciente desnudo, sin dejar de explorar surcos y pliegues, genitales, uñas, cuero cabelludo e identificando lesiones secundarias al rascado. No hemos de olvidar los ganglios linfáticos (adenopatías) ni la búsqueda de visceromegalias en abdomen.

3. Pruebas complementarias. - Inicialmente, solicitaremos analítica que incluirá hemograma completo, velocidad de sedimentación, ferritina, creatinina, glucemia, colesterol, bilirrubina total, transaminasas y hormonas tiroideas. Además, sedimento de orina, radiografía de tórax y estudio de huevos y parásitos en heces.

Pruebas más específicas como proteinograma, ecografía abdominal o biopsia cutánea se realizarán posteriormente, cuando la sospecha diagnóstica así lo recomiende.

En caso de no hallar alteración exploratoria y/o analítica alguna, inclinaremos nuestras sospechas hacia la sequedad de piel, especialmente en caso de pacientes ancianos, siempre pendientes de la evolución, recomendando la repetición de analíticas y exploración de modo periódico y sin perder de vista la posibilidad de encontrarnos ante una neoplasia oculta. ${ }^{2}$

Así, existen linfomas T y B que afectan a la 
DIAGNÓSTICO DIFERENCIAL PRURITO*

CAUSAS CUTÁNEAS

Infestación

-Pediculosis, escabiosis, picaduras.

-Infestación animales de compañía

Enfermedad inflamatoria

-E. Ampollosas, dermatitis atópica y de contacto

-Psoriasis, miliaria, prurito acuagénico

-Hipersensibilidad a fármacos y erupción lumínica polimorfa

Enfermedad infecciosa

-Dermatofitosis

-Varicela

Otras

-Piel seca

-Mastocitosis cutánea

-Neoplasias

\section{CAUSAS SISTÉMICAS}

Enfermedad hematológica

-Ferropenia, mieloma, paraproteinemia, policitemia vera.

Linfomas y leucemias

-Linfoma Hodgkin y no Hodgkin

-Leucemia Mieloide Crónica

Neoplasias sólidas

-Adenocarcinoma de mama y estómago

-Tumores del SNC

Enfermedades endocrinas

-Diabetes M ellitus

- Hiper e hipoparatiroidismo

-Hiper e hipotiroidismo

Enfermedad hepatobiliar

Trastornos psicógenos

Fármacos

Otros procesos

-Síndrome Carcinoide

-Embarazo

-Mastocitosis

*Adaptada de cita 2.

piel de manera primaria o secundaria y constituyen aproximadamente el $2 \%$ de los linfomas no Hodgkin. La piel se comporta como un órgano linfoide $\mathrm{T}$ y por ello los linfomas más frecuentes en este órgano son linfomas de células $\mathrm{T}$, de los cuales la micosis fungoide y el síndrome de Sezary son los más frecuentes $(25 \%$ de todos los linfomas cutáneos ${ }^{3,4}$. Su etiología no ha sido aclarada, no siendo concluyentes los estudios que tratan de relacionarlos con el virus HTLV-1(virus linfotrópico de células T humanas) ni aquéllos que investigan posibles conexiones con anomalías cromosómicas, que en los últimos estudios, parecen ser sobre todo deleciones y traslocaciones en los cromosomas 1 ó 6. Otros estudios han demostrado asociación con antígenos de histocompatibilidad, mencionándose Aw31, Aw32, B8, Bw38 y DR5 5 .

El síndrome de Sezary es considerado como la expresión leucemizada de la micosis fungoide, caracterizándose por eritrodermia, poliadenopatías y un elevado número de linfocitos atípicos (células de Sezary) en sangre periférica. Los pacientes pueden presentar todos los componentes del síndrome o sólo uno, generalmente eritrodermia y desarrollar después otros. Afecta sobre todo a varones de avanzada edad y suele asociarse con una evolución más rápidamente agresiva que la de la micosis fungoide. Otros datos clínicos que se pueden presentar en este cuadro son hiperpigmentación progresiva, hiperqueratosis palmoplantar y la pérdida de pelo y uñas ${ }^{5,6}$.

La micosis fungoide, descrita por vez primera en Francia en 1806, es un linfoma T postímico de bajo grado de malignidad cuya primera manifestación tiene lugar en la piel pero que al ser un proceso neoplásico afecta a la totalidad del sistema linforreticular durante el curso de la enfermedad. La edad de presentación más frecuente se encuentra entre 55 y 60 años con una relación varón/mujer de $2: 1$ y una incidencia de 2 casos por cada millón de habitantes ( $1 \%$ de muertes a causa del linfo$\mathrm{ma})^{5,7}$.

Su evolución es lenta, cursando en 3 etapas:

1. Fase premicótica. - Áreas maculares bien delimitadas, pruriginosas, en tronco y zonas no expuestas que mejoran tras la exposición solar. 
2. Fase infiltrativa.- Una o varias lesiones se infiltran, dando lugar a placas circinadas hiper o hipopigmentadas. Se puede asociar alopecia y/o mucinosis folicular.

3. Fase tumoral.- Aparecen tumores sobre placas infiltradas, precozmente o tras larga evolución, de consistencia firme y color rojo violáceo.

Al principio, pues, la enfermedad está limitada a la piel, pudiendo presentar durante meses o incluso años, lesiones relativamente inespecíficas diagnosticándose en ocasiones como parapsoriais o dermatitis inespecíficas. Suelen ser grandes placas rojizas, descamativas o no, asociadas generalmente con prurito, en un principio superficiales, de localización aleatoria y que, posteriormente, adquieren carácter infiltrativo o de auténtica eritrodermia exfoliativa difusa, que puede acompañarse de piel atrófica o liquenificada. En ocasiones, evolucionan a tumoraciones ulceradas o exofíticas ${ }^{3-5,7}$.

En las fases más avanzadas puede haber adenopatías o visceromegalias. La posibilidad de desarrollar afectación extracutánea tiene correlación con la extensión cutánea, siendo mayor (30-42\%) en pacientes con eritrodermia generalizada.

La prueba principal para el diagnóstico será la biopsia cutánea, la cual demuestra en epidermis y dermis superior la presencia de células mononucleares atípicas, que pueden agregarse formando los microabscesos de Pautrier. Esta confirmación histológica del diagnóstico puede ser imposible durante años pese a lo típico de las lesiones ${ }^{3-5,7}$.

Si se produce afectación en sangre periférica, se considera que estos pacientes presentan síndrome de Sezary. La leucocitosis puede ser moderada $\left(10-15 \times 10^{3} / \mathrm{mm}^{3}\right)$ o extrema (superior a $200 \times 10^{3} / \mathrm{mm}^{3}$ ). Los linfocitos atípicos que presentan en sangre se denominan células de Sezary siendo su característica principal la irregularidad de su núcleo, que adopta forma cerebriforme. Actualmente, es discutido el porcentaje de células de Sezary en sangre periférica que define un síndrome de Sezary. Mientras el National Cancer Institute (NCI) precisa una cifra superior al 5\%, otros centros de referencia señalan hasta un $20 \%$ de linfocitos o un número total de $1.000 / \mathrm{mm}^{3} \mathrm{de}$ células de Sezary. Estudios de citometría de flujo muestran expansión de la población $\mathrm{CD} 4{ }^{+} \mathrm{CD} 7$, reflejo de los linfocitos atípicos circulantes ${ }^{5,6,8}$.
Obviamente, los pacientes con síndrome de Sezary tienen peor pronóstico que aquéllos con micosis fungoide, empeorándolo también la presencia de síntomas "B", y niveles altos de LDH (lactatodeshidrogenasa) en sangre. La supervivencia media en pacientes con enfermedad extracutánea, bien afectación linfática, bien visceral, se encuentra entre 2 y 19 meses $^{8}$.

Los progresos en el tratamiento de los linfomas cutáneos de células T dependerán de los avances en el conocimiento de la enfermedad a nivel molecular. La posible influencia de la flora cutánea u otros antígenos en la proliferación inicial podría dar un nuevo enfoque al problema, así como abrir otras vías o estrategias encaminadas a preservar la función inmune en estos pacientes ${ }^{9}$.

El tipo de tratamiento vendrá determinado por el estadio de la enfermedad; en estadios primarios se emplea tratamiento tópico con aplicaciones de mostaza (mecloretamina), puvoterapia con o sin radioterapia convencional o electroterapia. Otra modalidad es la fotoquimioterapia extracorpórea. Se han efectuado pruebas con nuevos retinoides más selectivos y con menos efectos secundarios. En fases más avanzadas se emplean, como tratamiento sistémico, poliquimioterapias como las empleadas en linfomas de alta malignidad, siendo la combinación más efectiva la formada por ciclofosfamida, vincristina y prednisona (CHOP) con o sin doxorubicina. La ausencia de estudios randomizados hace difícil hablar de la eficacia del tratamiento actual sobre la supervivencia ${ }^{5,6,9}$.

La experiencia con trasplante autólogo de médula ósea es muy limitada y se encuentran en estudio el uso de anticuerpos monoclonales anti-células $\mathrm{T}$ y la fusión de proteínas recombinantes, siendo aprobado recientemente el uso, en micosis fungoide y síndrome de Sezary refractarios, de la primera de ellas: DAB(389) IL-24.

CORRESPONDENCIA:

Juan Manuel Pinar Manzanet

$\mathrm{C}$ / Fuente de Lima $364^{\circ} \mathrm{C}$

28024 Madrid 


\section{Bibliografía}

1. Verbov J. Alteraciones de la piel. En: Norman Exten A, Weksler M. Geriatría en atención primaria. $1^{\text {a }}$ ed. Barcelona: Editorial lúdica JIMS S.L. 1999: 197-212.

2. Samly AH. Diagnóstico clínico en Medicina. Madrid: Ed. Doyma, 1992; 728-32.

3. Fitzpatrick TB, Polano MK, Suurnond D. Atlas de Dermatología Clínica. Edición española. Barcelona: Doyma, 1992.

4. Siegel RS, Pandolfino T, Guitart J, Rosen S, Kuzel TM. Primary cutaneous T-cell lymphoma: review and current concepts. J Clin Oncol 2000 Ago; 18 (15): 2908-25.

5. Kim YH, Hoppe RT. Mycosis Fungoides and the Sezary Syndrome. Seminars in Oncology 1999 Jun; 26 (3) 276-89.

6. Russel-Jones R, Whittaker S. Sezary syndrome: diagnostic criteria and therapeutic options. Semin Cutan Med Surg 2000 Jun; 19 (2): 100-8.

7. Howard MS, Smoller BR. Mycosis fungoides: classic disease and variant presentations. Semin Cutan Med Surg 2000 Jun; 19 (2): 91-9.

8. Grange F, Hedelin G, Joly P, Beylot-Barry M, D'Incan M, De la Unay M, et al. for the French study group on cutaneous lymphomas (FSGCL). Prognostic factors in primary cutaneous lymphomas other than mycosis fungoides and the Sezary syndrome. The French Study Group on cutaneous lymphomas. Blood 1999 Jun; 93 (11): 3637-42.

9. Duvic M, Cather JC. Emerging new therapies for cutaneous T-cell lymphoma. Dermatol Clin 2000 Ene; 18 (1): 147-56. 